\title{
Excess Pore Pressure and Slope Failures Resulting From Gas-Hydrates Dissociation and Dissolution
}

Nabil Sultan, Ifremer

Copyright 2007, Offshore Technology Conference

This paper was prepared for presentation at the 2007 Offshore Technology Conference held in Houston, Texas, U.S.A., 30 April-3 May 2007.

This paper was selected for presentation by an OTC Program Committee following review of information contained in an abstract submitted by the author(s). Contents of the paper, as presented, have not been reviewed by the OHshore Technology Conference and are subject to correction by the auhor(s). The materlal, as presented, does not necessarly reflect any position of the OHshore Technology Conference, its officers, or members. Papers presented at OTC are subject to publication review by Sponsor Society Committees of the Offshore Technology Conference. Electronic reproduction, distribution, or storage of any part of this paper for commercial purposes without the written consent of the Offshore Technology Conference is prohibited. Permission to reproduce in print is restricted to an abstract of not more than 300 words; illustrations may not be copied. The abstract must contain conspicuous acknowledgment of where and by whom the paper was presented. Write Librarian, OTC, P.O. Box 833836, Richardson, TX 75083-3836, U.S.A., fax 01-972-952-9435.

\begin{abstract}
Parameters affecting gas hydrate formation include temperature, pore pressure, gas chemistry, and pore-water salinity. Any change in the equilibrium of these parameters may result in dissociation (gas-hydrate turns into free gas/water mixture) and/or dissolution (gas-hydrate becomes mixture of water and dissolved gas) of the gas hydrate. While, gas-hydrate dissociation at the base of the Gas Hydrate Occurrence Zone (GHOZ) is often considered as a major cause of sediment deformation and submarine slope failures the consequence in terms of pore pressure and sediment deformation of the dissolution of the gas hydrate at the top of the GHOZ remains neglected. In this study, we quantify and compare the excess pore pressure resulting from gas hydrate dissociation and dissolution. Based on theoretical development it is demonstrated that excess pore pressure and shear discontinuities generated by hydrate dissociation is unlikely to be a hazardous factor. In natural environment, the excess pore pressure generated by hydrate dissociation is bounded by the gas hydrate stability law inducing for a natural temperature increase a limited amount of excess pore pressure and limited shear discontinuities at the base of the GHOZ. On the other hand, we show that under natural temperature changes hydrate dissolution at the top of the gas hydrate stability zone, which can occur at a regional scale, is a hazardous process that can lead to catastrophic landslides.
\end{abstract}

\section{Introduction}

For the last 3 decades, several authors have raised serious concerns regarding the possible link between gas hydrate and submarine slope failures. McIver ${ }^{1}$ was amongst the first authors to speculate about this possible link. In the McIver conceptual model ${ }^{1}$, the excess pore pressure generated by hydrate dissociation and the sediment shear strength decreases (lost of hydrate playing the role of cementing agent between sediment grains) are the two key factors in the slope failure mechanism. The causal factor of the hydrate dissociation in McIver ${ }^{1}$ model is the continuous sedimentation, which induces the upward migration of the base of the Gas Hydrate Stability Zone (GHSZ). Afterwards, Kvenvolden ${ }^{2}$ has stated that an upward movement of the bottom of the GHSZ due to an increase of bottom water temperature may accelerate the process of slope failures associated to hydrate dissociation. Different authors have later developed several other hypotheses and theories supposing all that gas hydrate dissociation may lead to important excess pore pressure and lead to sediment deformations and slope instabilities ${ }^{3,4,5,6,7}$. In the meantime, many large submarine landslides have been described worldwide in areas where gas hydrate occurrence was proved or suspected ${ }^{9,10,11,12,13}$. Paull and co-authors ${ }^{6}$ have proposed that gas-hydrate is the main cause of the increased frequency of sea-floor slumping on continental margins containing gas hydrates during sea-level lowstands. While authors seem to agree about the association between gashydrate dissociation and submarine slope failures, few theoretical and mathematical works were developed to define accurately the mechanism associated to the slope failure process. In the last few years, some authors have tried to evaluate using different approaches the excess pore pressure due to hydrate dissociation ${ }^{14,15,16,17,18}$. On the other hand, almost none or very few theoretical and experimental works were carried out to identify the decrease of the sediment shear strength with hydrate dissociation.

The process of hydrate dissolution and slope failure was described previously by Sultan and co-authors ${ }^{16}$ to illustrate one of the possible triggering mechanisms of the Storegga slide. More recently, it was shown that the excess pore pressure generated by hydrate dissolution seems to be in the same order of magnitude than the one generated by hydrate dissociation under undrained conditions and for a closed system $^{17}$. On the other hand, the gas hydrate stability law bounds the amount of the excess pore pressure generated by gas-hydrate dissociation. By considering theoretically the two processes of hydrate dissolution and hydrate dissociation, our work aims to give an answer to the following major question: Under natural sea level and temperature changes as the one occurred since the last deglaciation where is the most hazardous area in the GHOZ of submarine slopes? 


\section{Excess pore pressure generated by hydrate dissolution and dissociation}

The excess pore pressure generated by hydrate dissolution and dissociation in a closed system can be derived from the compressibility of the gas hydrate-bearing sediment system and the volume and expansion factor of each constituent (solid, liquid and gas) ${ }^{16,17,18}$. While the volume expansion factor generated by the gas hydrate dissociation is much larger than the one generated by hydrate dissolution, the compressibility of a system containing free gas is much higher than the one containing just liquid. The amount of the excess pore pressure generated by the two processes of hydrate dissolution and dissociation is bounded by the gas hydrate stability law and the gas solubility respectively.

\section{Upper bound of the excess pore pressure resulting from hydrate dissociation process}

Figure 1 shows the results of $1 \mathrm{D}$ calculation in terms of excess pore pressure generated by hydrate dissociation due to a temperature increase from an initial thermal state $T_{i}$ to a final one $T_{f}$ using the software developed by Sultan and coauthors ${ }^{16}$. In this calculation the transient thermal evolution from $T_{i}$ to $T_{f}$ is not considered in order to focus on the excess pore pressure generated between two limiting temperature states. Under $T_{i}$, gas hydrates are stable over the first $200 \mathrm{~m}$ (Figure 1-a). For a thermal steady state regime from $T_{i}$ to $T_{f}$, the temperature increase induces the dissociation of the gas hydrate below the point $\mathrm{A}$ in Figure 1-a. However, the gas hydrates are not completely dissociated below the point $\mathrm{A}$ since the excess pore pressure generated by the hydrate dissociation re-crystallizes a part of the hydrate and delays hydrate dissociation process. This phenomenon creates a metastable thermodynamic state where the gas and the gashydrates coexist (Figure 1-b-c). The excess pore pressure cannot cross the hydrate stability curve as presented in Figure 1-d showing that the BHSZ which is often associated to the BSR is an area with a dynamic process where the free gas concentration and the excess pore pressure are the lowest. In such dynamic process where the gas hydrate is dissociating at the base of the gas hydrate stability zone, the sharp limit between gas hydrate and the free gas is not very clear as it can be seen from Figure 1. The subsequent dissipation of the pore pressure below the base of the GHSZ generates an additional dissociation of the gas hydrate. The time scale of this dissipation depends on the permeability of the sediment. At long term the gas hydrate below the GHSZ may disappear completely without the generation of a critical pore pressure at the base of the GHOZ.

The upper bound of the excess pore pressure $\Delta u_{\max }$ generated by hydrate dissociation can therefore be calculated from the following equation:

$$
\left.\Delta u_{\max }\right|_{z(T)}=P(T)-z(T) \cdot \gamma_{w}
$$

where $P(T)$ is the hydrate equilibrium pressure at a given temperature $T, z(T)$ is the depth corresponding to the same temperature $T$ and $\gamma_{w}$ is the water unit weight.

\section{Upper bound of the excess pore pressure resulting from the hydrate dissolution process}

The upper bound of the excess pore pressure generated by hydrate dissolution is related to the solubility of the gas. The low solubility of the methane prevents to form easily in the laboratory methane-hydrate from a single-phase solution of dissolved methane in water. However, it was demonstrated theoretically that dissolution of methane hydrate in a closed system leads to a decrease of the mass density and therefore to an increase of the pore pressure ${ }^{17}$. For methane hydrate, the maximum excess pore pressure generated by hydrate dissolution can be evaluated using the analytical expressions given by Sultan ${ }^{17}$ and is presented in Figure 2. The maximum hydrate fraction able to be dissolved in seawater is presented as a function of depth in Figure 2-a. The maximum excess pore pressure generated by hydrate dissolution is presented in Figure 2-b.

\section{Slope failure and Shear band propagation associated to gas hydrate dissolution and dissociation}

The effect of hydrate formation on the increase of the shear resistance of hydrate-bearing sediments has been well recognized experimentally ${ }^{20,21}$. This increase of the shear resistance depends mainly on the gas hydrate distribution (disseminated in the pores versus cementing grains) and the gas hydrate fraction. The increase of the shear resistance is optimal when gas hydrate acts as a cementing agent between grains. Sultan ${ }^{17}$ has recently carried out in-situ CPT (Cone Penetration Testing) measurements in hydrate-bearing sediments. In-situ mass density using a source of Cesium 137 was also acquired. From the mass-density and the cone resistance $q t$, it was possible to calculate the hydrate fraction $\eta$ and the internal friction angle $\varphi$. Results from [17] have clearly shown the effect of the hydrate fraction on the increase of the internal friction angle. An important increase of the internal friction angle was observed at low hydrate fraction $(<$ $2 \%)$.

On the other hand, hydrate formation impede the normal mechanical consolidation of the hydrate-bearing sediment leading to the formation of an open sediment structure. The phenomenon of hydrate dissolution and dissociation in the GHSZ is probably similar to destructuration and softening of natural clay. Several authors have shown experimentally an important deformation and collapse due to the destructuration of natural clay ${ }^{22,23}$. Recently, Yun and Santamarina ${ }^{21}$ have observed that sediment with only $2 \%$ of cemented material may strengthen the sediment matrix and create an open structure. The subsequent mechanical loading of this cemented sediment has induced the collapse of the cemented structure. Hydrate dissolution/dissociation may lead to an important plastic deformation (collapse) of the sediment due to the loss of cementation. Therefore a localized shear strain at the top or the bottom of the GHOZ may create shear discontinuities.

One of the key parameters in the evaluation of the slope 
instability enclosing gas hydrate is the lateral extension of the area where gas hydrate was dissolved or dissociated (shear discontinuities) due to the temperature and hydrostatic pressure changes. The amount of the excess pore pressure generated by hydrate dissolution/dissociation is also an important input to evaluate the danger of slope failures. In this work, the location of the hydrate dissolution/dissociation areas and the excess pore pressure generated by dissolution and dissociation was evaluated based on the theoretical development presented by Sultan and co-authors ${ }^{16,17}$. In this work, hydrofracturing is supposed to occur in sediment whenever the excess pore pressure has exceeded 95\% of the vertical effective stress. In the lack of experimental data and as a hypothesis, hydrofracturing was also considered to occur only in gas-hydrate marine sediment with hydrate fraction lower than 1. After hydrofracturing, the permeability of the hydrofractured sediment increases until the excess pore pressure becomes equal or less to $95 \%$ of the vertical effective stress.

Figure 3 shows the initial distribution of the hydrate fraction for a gentle submarine slope (slope angle of $2.2^{\circ}$ ) in water depths ranging between 450 and $850 \mathrm{~m}$. Figure 4 illustrates the temperature and hydrostatic pressure increments applied at each time period and considered in this work as the source of the hydrate dissolution and dissociation along the considered submarine slope. The initial seawater temperature was taken equal to $3.2^{\circ}$ and the temperature gradient equal to $40^{\circ} \mathrm{C} / \mathrm{km}$ (time 0 - Figure 4).

Figure 5 presents the amount and location of dissolved or dissociated hydrates (shear discontinuities), the pore pressure field and the base of the GHSZ generated after $0.8 \mathrm{ky}, 1.2 \mathrm{ky}$, 2 ky and 4 ky of temperature and hydrostatic pressure increases. Excess pore pressure generated by hydrate dissolution is related to the increase of the gas solubility as the temperature and pressure increases ${ }^{16,17}$. From Figure 5, one can see that critical pore pressure was first generated at the top of the GHOZ. The spatial extension of the pore pressure and the hydrate fraction decreases which define the extension of the shear discontinuities are much more important at the top of the GHOZ than at its base. This is due to the relatively fast temperature rises at the top of the GHOZ with respect to the bottom of the GHOZ. The excess pore pressure at the base of the GHOZ has delayed the dissociation process and it autocontrols the dissociation process preventing the generation of excess pore pressure exceeding the pressure of the thermodynamic stability of the gas hydrate (Figure 5).

The shear discontinuities corresponding to the hydrate dissolution and dissociation areas can be used to evaluate the danger of a catastrophic landslides generation. Puzrin and coauthors $^{24}$ have recently applied the fracture mechanics methods to evaluate the shear band propagation in soils and its consequence in terms of catastrophic landslides generation. Puzrin and co-authors ${ }^{24}$ have combined limiting equilibrium to fracture mechanics and have showed clearly that the main parameters controlling the shear band propagation and the generation of catastrophic landslide are:

- $\quad$ the depth of the discontinuity surface $h$

- $\quad$ the length of the discontinuity surface $L$

- $\quad$ the residual shear strength along the discontinuity surface $\tau_{\mathrm{r}}$
- $\quad$ the gravitational shear stress $\tau_{g}$ which is equal to $\gamma^{\prime} \cdot h \cdot \sin (\alpha): \gamma^{\prime}$ is the submerged unit weight and $\alpha$ is the slope angle

- $\quad$ the average values of the active $\left(P_{a}\right)$ and passive $\left(P_{p}\right)$ lateral pressure in the considered layer.

To generate catastrophic landslides Puzrin and co-authors ${ }^{24}$ have shown that the length of the discontinuity surface $L$ must be greater than the length of the critical shear band $l_{f}$ which is given by the following equation:

$$
L>l_{f}=h \frac{P_{p}-P_{a}}{\tau_{g}-\tau_{r}}
$$

\section{Discussion}

Observations on continental slopes in zones with proven or suspected gas hydrate occurrence and sediment deformations show that slope failure could be initiated inside or even at the top of the $G H S Z^{25,26}$. Pecher and co-authors ${ }^{25}$ have described seafloor erosion associated to hydrate destabilization caused by depressurization during ridge uplift and fluctuating water temperatures. Brown and co-authors ${ }^{26}$ have rejected gas hydrate dissociation as a triggering mechanism of the Storegga Slide, on the fact that the bottom simulating reflector (BSR) would have been deeper than the glide plane at the time of Storegga slope failure. Those examples show that in natural environment slope failures are not always associated to hydrate dissociation at the base of the GHOZ and that slope failure may occur due to hydrate dissolution at the top of the GHOZ.

Calculation results obtained in this work and presented in Figure 5 demonstrate that hydrate dissolution at the top of the GHOZ occurs earlier than the hydrate dissociation at the base of the GHOZ. In this work, the Puzrin and co-authors ${ }^{24}$ criterion was used to evaluate the danger of a catastrophic landslides generation after $0.8 \mathrm{ky}$ of temperature and pressure increase (Figure 6). It is clear from Figure 6, that the length of the shear discontinuity at the top of the GHOZ is much more important than the one at the base of the GHOZ $\left(L_{b}<L_{t}\right)$. Moreover, the critical length of the shear band $l_{f}$ needed to generate catastrophic landslides is much lower at the top than at the base of the GHSZ $\left(\left.l_{f}\right|_{\text {base }}>\left.l_{f}\right|_{\text {top }}\right)$ since:

- The value of the passive lateral pressure in the hydrate layer $\left(P_{p b}\right)$ is more important than the one in the saturated soil $\left(P_{p t}\right)$ : the passive lateral pressure depends on the shear strength of the medium which increases with the hydrate fraction;

- The value of the active lateral pressure $P_{a}$ in the hydrate layer is equivalent to the one in the saturated soil (Figure 6);

- $\quad$ The depth of the discontinuity surface $h_{t}$ at the top of the GHSZ is greater than the one at the base of the GHSZ $h_{b}$ (Figure 6);

- $\quad$ The residual shear strength along the top $\tau_{r t}$ is lower than the $\tau_{r b}$ due to the increase of the effective stress with depth. Moreover, the amplitude of the excess 
pore pressure which can reduce the shear strength significantly seems to be more important at the top than the bottom of the GHOZ.

- $\quad$ The gravitational shear stress $\tau_{g}$ increases with depth due to the load of the sediment above the discontinuity surface. However and due to the low slope angle of submarine slopes the increase of $\tau_{g}$ could be considered as negligible with respect to the other parameters of equation 1: for a slope angle of $2.2^{\circ}$ and a mean submerged unit weight of $5 \mathrm{kN} / \mathrm{m}^{3}$ at the dissolution level and $7 \mathrm{kN} / \mathrm{m}^{3}$ at the dissociation one, the value of $\frac{\tau_{g}}{h}$ is equal to $0.26 \mathrm{kN} / \mathrm{m}$ at the dissolution level while it is equal to $0.192 \mathrm{kN} / \mathrm{m}$ at the dissociation one.

From the above 5 observations derived from Figure 5, Figure 6 and equation 2, it is clear that catastrophic slope failure is more likely to happen at the top than the bottom of the GHOZ. Moreover, sediment deformation associated to the hydrate dynamic under a natural temperature and pressure increase as the one occurred since the last deglaciation is expected to occur first at the top of the GHOZ.

\section{Conclusion}

The main aim of this paper was to evaluate the danger related to the gas hydrate dissociation and dissolution under natural sea level and temperature changes as the one occurred since the last deglaciation. Based on theoretical calculation, it was clear that the top of the GHOZ is much more hazardeous than its bottom:

- The excess pore pressure generated at the base of the GHOZ can re-crystallise the gas hydrate and delay the dissociation process.

- Gas hydrate dissociation under natural sea level and temperature changes seems to be a slow process rather than a catastrophic event and it plays an autocontrolling role in the hydrate dissociation progression.

- The lateral extension of the gas hydrate dissolved area is much larger and more regional than the dissocated one.

- Geometrical and mechanical conditions of the propagation of the shear band, which is the main factor in generating catastrophic event, seems to be more likely to happen at the top rather than the bottom of the GHOZ.

\section{Acknowledgement}

I am grateful to Jean-Paul Foucher for his valuable discussions and comments.

\section{References}

1. McIver, R. D.: "Role of naturally occurring gas hydrates in sediment transport.", American Association of Petroleum Geologists Bulletin (1982), 66, 789.

2. Kvenvolden, K. A.: "Natural gas hydrate occurrence and issues.”, Ann. N.Y. Acad. Sci. (1994), 715, 232.

3. Kayen, R.E.: "Arctic Ocean landslides and sea-level fall induced gas hydrate decomposition.”, MS thesis, Californian State University, Hayward (1988), 227 p.

4. Kayen, R. E. and Lee, H. G.; "Pleistocene slope instability of gas hydrate-laden sediment on the Beaufort Sea margin.”, Mar. Geotechnol. (1991), 10, 125.

5. Kvenvolden, K.A.: "Potential effects of gas hydrate on human welfare.”. Proc. Natl. Acad. Sci. USA (1999), 96, 3420.

6. Paull, C.K., Buelow, W.J., Ussler, W. and Borowski, W.S.: "Increased continental- margin slumping frequency during sealevel lowstands above gas hydratebearing sediments.", Geology (1996), 24, 143.

7. Paull, C., Ussler, W. and Dillon, W.: "Potential role of gas hydrate in generating submarine slope failures.”. In Max, M. (Ed.), Natural Gas Hydrate in Oceanic and Permafrost Environments: Amsterdam (Klewer) (2000), 149.

8. Paull C.K., Rehder G., Clague D., Brewer P.G., Ussler W. III and Peltzer E.T.: "An experiment demonstrating that marine slumping is a mechanism to transfer methane from seafloor gashydrate deposits into the upper ocean and atmosphere.", Geo-Marine Letters (2003), 22, 198.

9. Summerhayes, C. P., Bornhold, B. D. and Embley, R. W.: "Surficial slides and slumps on the continental slope and rise off South West Africa: a reconnaissance study.”, Mar. Geol. (1979), 31, 265.

10. Carpenter, G.: "Coincident sediment slump/clathrate complexes on the U.S. Atlantic conti-nental slope.”, Geo-Mar. Lett. (1981) 1, 29.

11. Jansen, E., Befring, S., Bugge, T., Eidvin, T., Holtedahl, H. and Sejrup, H. P.: "Large submarine slides on the Norwegian continental margin: sediments, transport and timing." Mar. Geol. (1987), 78, 77.

12. Kayen, R.E. and Lee, H.J.: "Slope stability in regions of sea-floor gas hydrate.”. In Schwab, W.C., Lee, H.J., and Twichell, D.C. (Eds.), Submarine Landslides: Selected Studies in the U.S. Exclusive Economic Zone. U.S. Geol. Surv. Bull. (1993), 97.

13. Bugge, T., Befring, S., Belderson, R. H., Eidvin, T., Jansen, E., Kenyon, H., Hotedahl, H. and Sejrup, H. P.: "A giant three-stage submarine slide off Norway”, Geo-Mar. Lett. (1987) 7, 191-198.

14. Flemings, P. B., Liu, X. and Winters, W.J.: "Critical pressure and multiphase flow in Blake Ridge gas hydrates.", Geology (2003), 31, 1057.

15. Hornbach, M., Saffer, D.M. and Holbrook, W.S.: "Critically pressured free-gas reservoirs below gas-hydrate provinces.", Nature (2003), 427, 142. 
16. Sultan, N., Cochonat, P., Foucher, J.-P. and Mienert, J.: "Effect of gas hydrates melting on seafloor slope instability.", Marine Geology (2004), 213, 379.

17. Sultan, N.: "Comment on Excess pore pressure resulting from methane hydrate dissociation in marine sediments: A theoretical approach. by Wenyue Xu and Leonid N. Germanovich.”, J. Geophys. Res. (2007), doi:10.1029/2006JB004527.

18. Xu, W. and Germanovich, L.N.: "Excess pore pressure resulting from methane hydrate dissociation in marine sediments: A theoretical approach.”, J. Geophys. Res. (2006), 111, doi:10.1029/2004JB003600.

19. Zhang, Y.: "Formation of hydrate from single-phase aqueous solutions.”, internal report (2003), 77 pp., Univ. of Pittsburgh, Pittsburgh

20. Winters, W.J., Pecher, I.A., Waite, W.E. and Mason, D.H.: “ Physical properties and rock physics models of sediment containing natural and laboratory-formed methane gas hydrate.", American Mineralogist (2004), 89, 1221.

21. Yun, T.S., and Santamarina, J.C.: "Decementation, softening and collapse: Changes in small-strain shear stiffness in Ko-loading." Journal of Geotechnical and Geoenvironmental Engineering. ASCE (2005), 131, 350.

22. Burland, J.B.: "On the compressibility and shear strength of natural clays.”, Géotechnique (1990), 40, 329.

23. Leroueil, S. and Vaughan, P.R.: "The general and congruent effects of structure in natural soils and weak rocks.", Géotechnique (1990), 40, 467.

24. Puzrin, A.M., Germanovich, L.N. and Kim, S.: "Catastrophic failure of submerged slopes in normally consolidated sediments.”, Géotechnique (2004), 54, 631.

25. Pecher I. A., Henrys, S. A., Ellis, S., Chiswell, S.M. and Kukowski, N.: "Erosion of the seafloor at the top of the gas hydrate stability zone on the Hikurangi Margin, New Zealand.", Geophys. Res. Lett. (2005), 32, L24603, doi:10.1029/2005GL024687.

26. Brown, H., Holbrook, W. S. Hornbach, M.J. and Nealon, J.: "Slide structure and role of gas hydrate at the northern boundary of the Storegga Slide, offshore Norway.", Marine geology (2006), 229, 179.

\section{Nomenclature}

$\alpha \quad$ slope angle

$\triangle P \quad$ hydrostatic pore pressure increment

$\Delta u_{\max } \quad$ maximum excess pore pressure

$\varphi \quad$ internal friction angle

GHSZ gas hydrate stability zone

GHOZ gas hydrate occurence zone

$\gamma_{w} \quad$ water unit weight

$\gamma^{\prime} \quad$ submerged unit weight

$h$ depth of the discontinuity surface

$\eta \quad$ hydrate fraction

$L \quad$ length of the discontinuity surface

$l_{f} \quad$ length of the critical shear band

$P_{a} \quad$ active lateral pressure

$P_{p} \quad$ passive lateral pressure

$P(T) \quad$ hydrate equilibrium pressure for a given temperature $\mathrm{T}$

qt corrected cone resistance

$T$ temperature

$\tau_{g} \quad$ gravitational shear stress

$\tau_{r} \quad$ residual shear stress

$z(T) \quad$ vertical depth for a given temperature $T$ 
a)

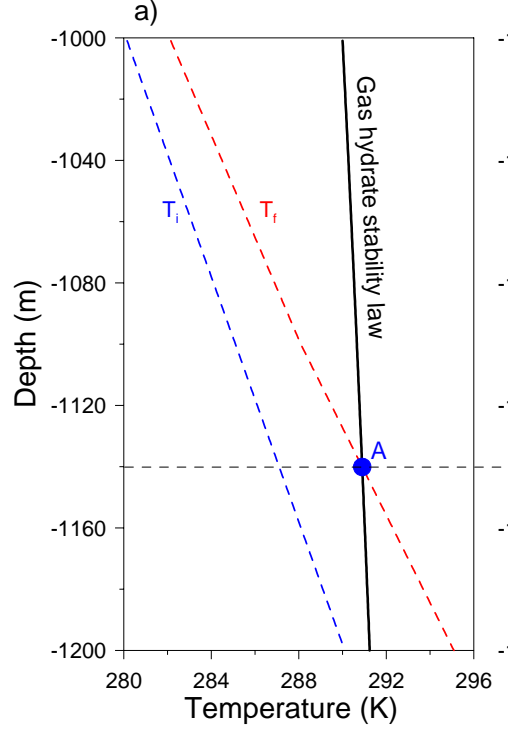

b)

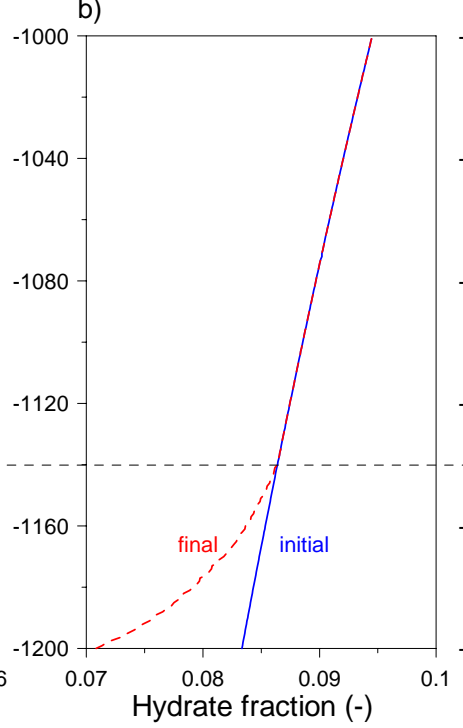

c)

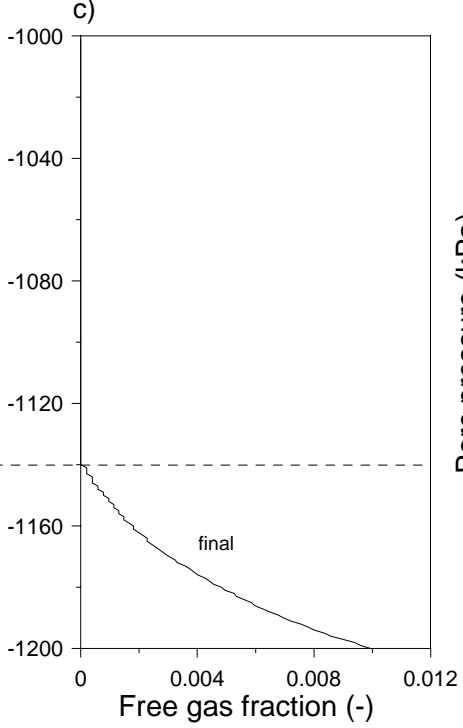

d)

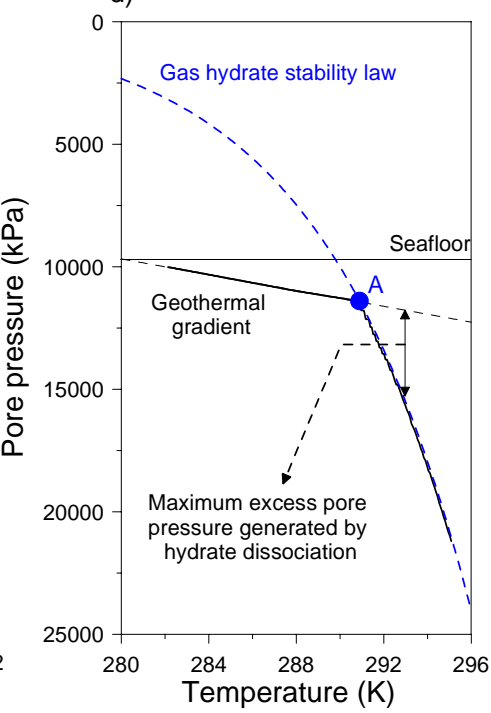

Figure 1. a) 1D calculation of gas hydrate bearing sediment system under two limiting thermal state showing a) the two temperature distributions $T_{i}$ and $T_{f} b$ ) hydrate fraction profiles under $T_{i}$ and $T_{f} c$ ) the free gas fraction profile under $T_{f}$ and d) the maximum possible excess pore pressure generated by hydrate dissociation for the considered calculation. The excess pore pressure and the free gas fraction generated by hydrate dissociation at the base of the hydrate stability zone (point A) is the lowest below the base of the GHSZ in a transient regime. The excess pore pressures re-crystallize the hydrate and induce a thermodynamic metastable state where the gas and the gas hydrate coexist.

a)

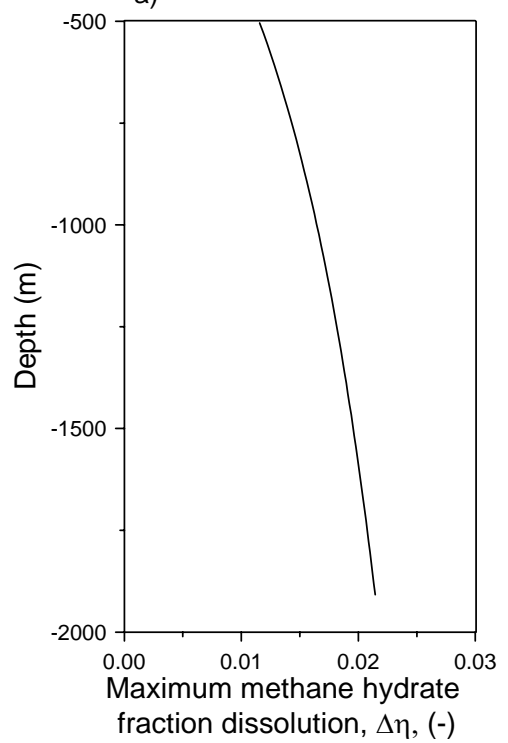

b)

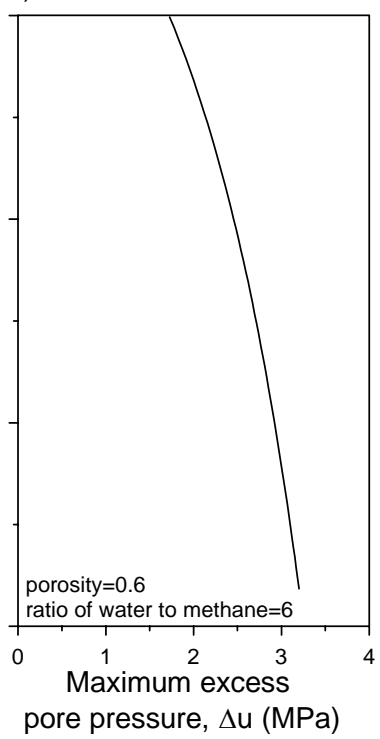

Figure 2. a) Maximum hydrate fraction dissolution as a function of water depth and b) maximum excess pore pressure generated by methane hydrate dissolution as a function of depth. 


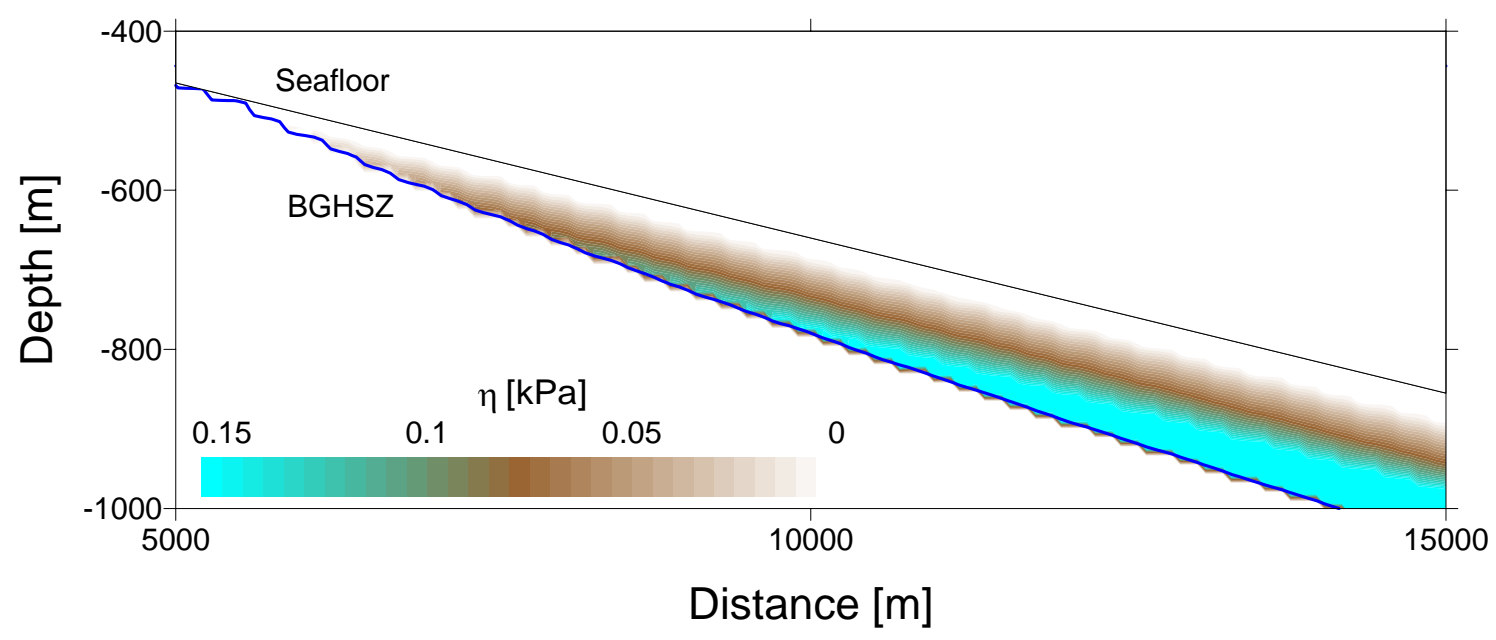

Figure 3. Initial hydrate fraction distribution

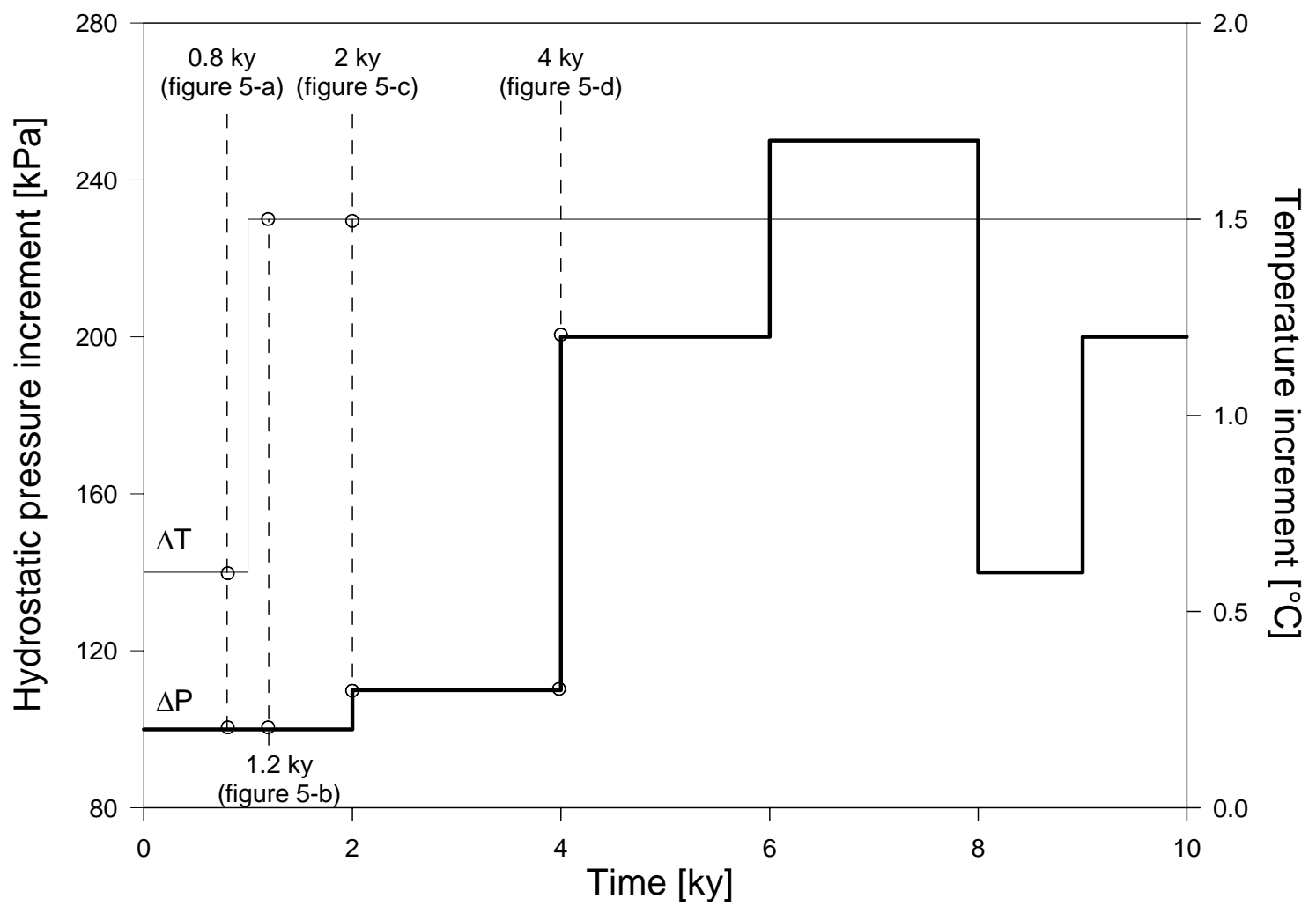

Figure 4. Temperature and pressure increments as a function of time. 

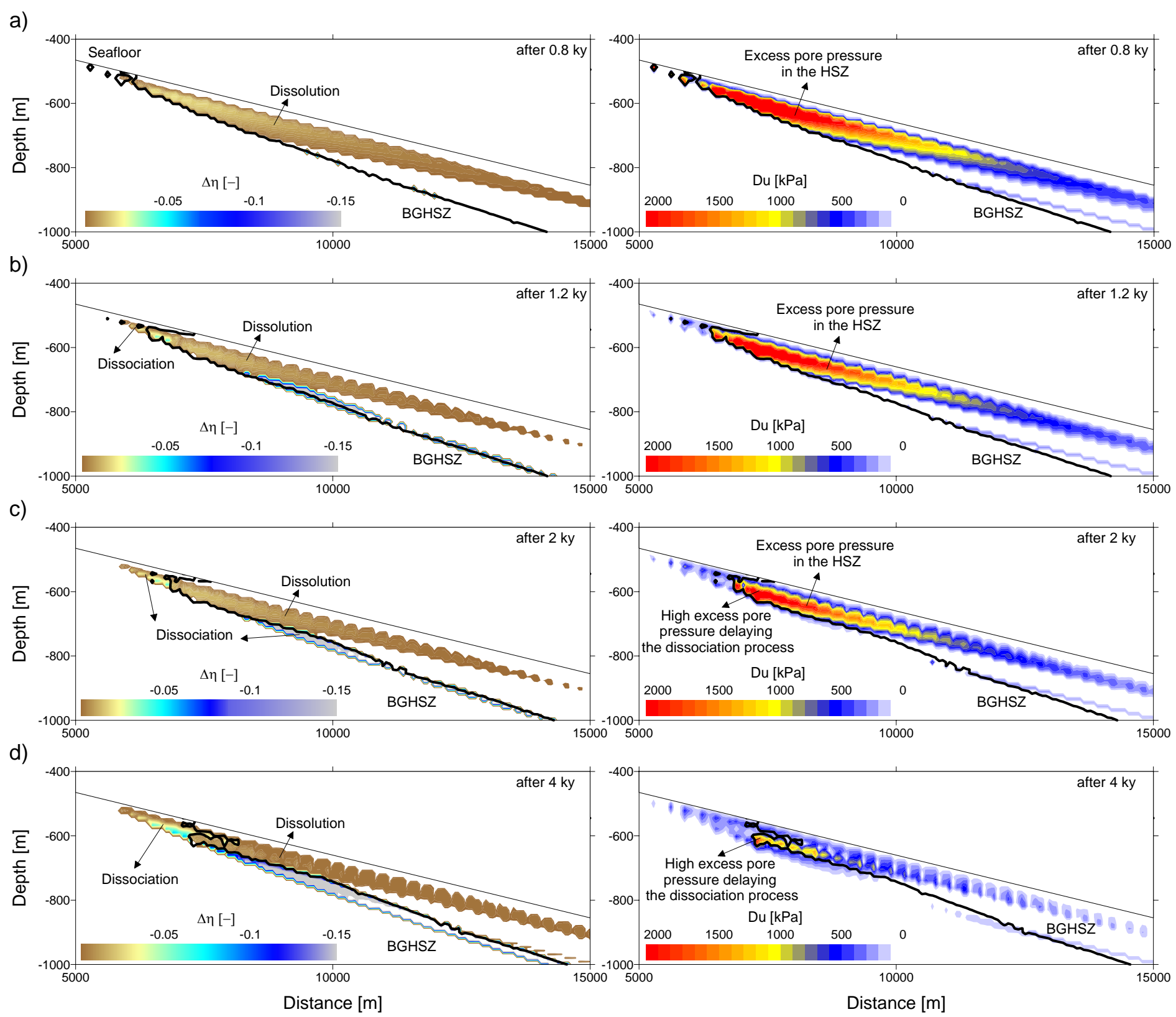

Figure 5. Amount and location of dissolved or dissociated hydrates (shear discontinuities), the pore pressure field and the base of the GHSZ generated after a) $0.8 \mathrm{ky} \mathrm{b}) \mathbf{1 . 2} \mathrm{ky}, \mathrm{c}) \mathbf{2} \mathrm{ky}$ and d) $4 \mathrm{ky}$ of temperature and hydrostatic pressure increases. 


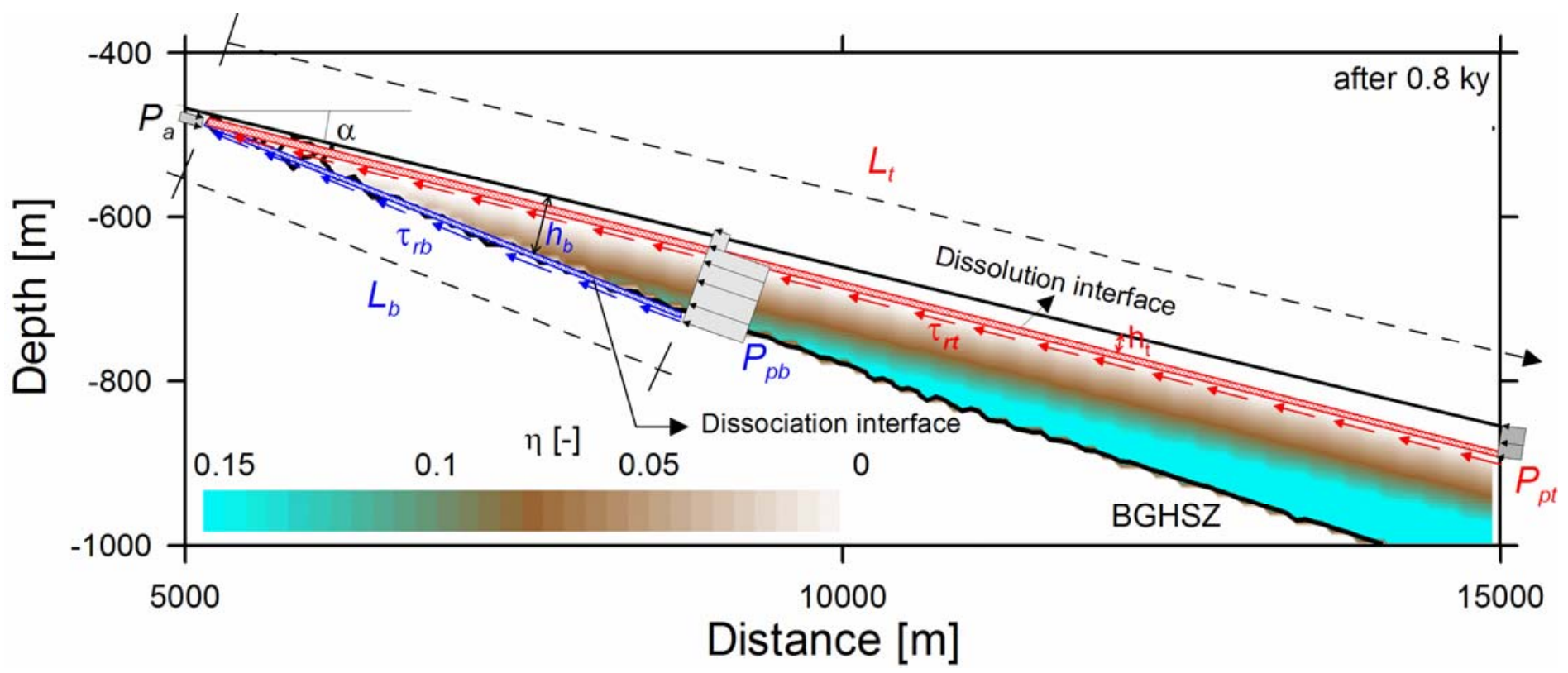

Figure 6. Shear band propagation caused by gas hydrate dissociation (at the bottom of the GHOZ) and dissolution (at the top of the GHOZ) after $0.8 \mathrm{ky}$ of sea level and temperature changes. 